\title{
Presentación. Más de 150 años de Charles BAUDELAIRE
}

Cristian Molina

Instituto de Estudios Críticos en Humanidades

Universidad Nacional de Rosario

Consejo Nacional de Investigaciones Científicas y Técnicas

molacris@yahoo.com.ar

Según la biografía célebre de Eugène Crépet (1906), el primero de septiembre de 1867, Asselineau anuncia a Paulet Malassis, en pocas líneas, un acontecimiento fúnebre: "Todo terminó. Murió ayer, a las once de la mañana, después de una larga agonía, pero tranquilo y sin sufrimiento. Estaba tan débil que no luchó más" (Crépet 1993, pp. 214. Traducción mía). Así, entre amigos se comunicaban la muerte de Charles Baudelaire, ocurrida, como vemos, el 31 de agosto de 1857, luego de una 'decadencia' afásica irrefrenable desde principios de 1856, que dejó al poeta sin poder expresarse más que por gestos y con unas pocas palabras. Era el poeta de la vida moderna como duelo y luto permanentes que habilitaría duelo y luto en ese presente, mientras dejaba varios libros, inconclusos o no, por venir, así como ediciones póstumas, homenajes, lecturas y una prensa ansiosa que desde hacía un año no vacilaba en escribir sobre su agónica salud y sobre su 'obra', no siempre en buenos términos. Lo que se alimentaba, así, era una parte del mito Baudelaire que sus amigos, luego, tratarían de conjurar, aunque con ese gesto no hicieran más que aumentarlo.

№ 8. Primer Semestre de 2018 
Entre el 31 de agosto y el 1 de septiembre de 2017 se cumplieron, entonces, 150 años de ese acontecimiento irrefrenable que puso en marcha una discursividad de luto y homenaje. Pero también durante el mes de agosto, se cumplieron 160 años del juicio condenatorio a Charles Baudelaire, que la Justicia imperial francesa llevó adelante de manos del implacable y vengativo fiscal Ernest Pinard por atentar contra las buenas costumbres al publicar un libro, también ese año, realista, grosero y ofensivo: Les fleurs de mal. Una fecha, entonces, marcada por tres acontecimientos del pasado (duelo, publicación, juicio) que, no sabemos bien, fueron activados por la escritura de Baudelaire o formaron parte de una performance extendida que atravesó el tiempo, en una suerte de presente prolongado, eternizado, hasta nuestros días.

Fue en ese marco que el 31 de agosto y 1 de septiembre de 2017, desde el Instituto de Estudios Críticos en Humanidades (IECH), el Centro de Estudios de Literatura Francesa (CELF), el Centro de Estudios de Literatura Argentina (CELA), el Centro de Estudios de Teoría y Crítica Literaria (CETYCLI) y la Escuela de Letras de nuestra Facultad, con colaboraciones de la Biblioteca Argentina Dr. Juan Álvarez y de la Agencia Shiva, llevamos adelante un Coloquio y actividades culturales extendidas a la comunidad sobre Charles Baudelaire. La propuesta llegó desde Alberto Giordano, quien estaba interesado en propiciar el encuentro entre diversos estudios y trabajos críticos que, en nuestro país, se realizaban sobre el poeta francés. El entusiasmo nos puso en contacto con Silvio Mattoni y Santiago Venturini para llevar adelante un trabajo 
colectivo que fue, paso a paso, desbordando las iniciales y modestas pretensiones de un Coloquio sobre estudios argentinos, hasta devenir latinoamericano. Y aquí estamos, en la tarea de este dossier que repone algunos de los aportes y estudios que se realizan actualmente sobre Charles Baudelaire.

Si los trabajos recientes de la crítica mundial abren o revisan algunos problemas sobre la práctica de Baudelaire en torno de las relaciones transdisciplinares y de las comunidades artísticas, como en La Folie Baudelaire (2011), de Roberto Calasso, o ponen el foco sobre las tensiones entre la poética baudelaireana y la República francesa, como el ensayo de Jacques Ranciere, "El gusto infinito por la República" incluido en El bilo perdido (2014), o revisan el carácter irreductible, pero fascinado por el dinero y el mercado, las tecnologías de la proximidad y la transformación urbana, de parte de Baudelaire, como Antoine Compagnon en Baudelaire, l'irréductible (2014), o retoman y redefinen la noción de experiencia benjaminiana para regresar sobre la de Baudelaire y contemporaneizarla, como Giorgio Agamben en Infancia e Historia (2001); en los estudios aquí presentados se retoman algunos de estos caminos, entre el ensayo y el artículo de investigación, para complejizarlos o para entrar, en otros casos, en abierta polémica e, incluso, para propiciar nuevas problemáticas.

De este modo, los trabajos de Silvia Tomas y Sergio Cueto avanzan sobre las relaciones entre Baudelaire con la fotografía o la música, mientras Laura Cozzo se centra en los usos que se realizan del poema "L'invitation au voyage" en la película con el mismo título de Germaine Dulac. David Fiel complejiza las 
proximidades y distancias, la irreductible "potencia de no" baudelaireana en las modalidades temporales de la monarquía, el segundo imperio y la República como modos complejos de relación con la política, desafiando la tesis ranciereana circunscrita a la República. En tanto, el trabajo de Mariano Sverdloff revisa los usos que la derecha nacionalista francesa realizó de Baudelaire en las primeras décadas del S XX. Walter Romero y Lucía Vogelfang abordan las derivas contemporáneas de la escritura sobre el París marginal baudelaireano en las escrituras de Anni Arnaux. Silvio Mattoni se concentra en la poética del duelo y el luto, así como Anahí Mallol analiza la angustia como potencia de la escritura baudelaireana. Carlos Surghi, junto con la traducción del texto de Marcelo Jacques de Moraes, realizado por Luciana Di Leone, retoman el tópico del presente, en el primer caso, para leer la fascinación deceptiva de Baudelaire que mantiene con él, y en el segundo, para explorar una fantasmagoría del fin que habilita dicha temporalidad. Magdalena Cámpora, en un recorrido exhaustivo y preciso por el archivo Baudelaire, analiza las derivas de la condena del juicio que pueden leerse en Le Spleen de Paris, y anticipa dos versiones de los poemas en prosa traducidos por Santiago Venturini. Por último, el texto de José Ramón Ruisánchez analiza la previa de la recepción de Baudelaire en México, con una tesis estimulante, según la cual la literatura mundial y sus movimientos e intercambios debe pluralizarse, por lo cual es mejor postular diversas literaturas mundiales de acuerdo a los contextos desde donde esta se estudie o focalice. 
Si las leemos en su conjunto, lo que esas constelaciones de diálogos, polémicas y nuevas preocupaciones parecen decirnos, más de 150 años después de las primeras publicaciones, del juicio y de su muerte, es que aún orbitamos de manera intensa en la contemporaneidad en torno de ese sol negro, silencioso y oximorónico que nos llega desde la antigua galaxia Baudelaire y cada uno de esos trabajos, al tiempo que se integran a ella, parecen invitarnos a leer y a gravitar ahí también.

\section{Referencias Bibliográficas}

\section{Bibliografía}

Agamben, Giorgio (2001). Infancia e historia. Buenos Aires: Adriana Hidlago.

Calasso, Roberto (2011). La Folie Baudelaire. Barcelona: Anagrama.

Compagnon, Antoine (2014). Baudelaire. L'Irréductible. Paris: Flammarion.

Crépet, Eugène (1993). Charles Baudelaire. Ginebra: Slatkine Reprints.

Rancière, Jacques (2015). "El gusto infinito por la República" en El hilo perdido. Buenos Aires: Manatial, pp. 89-105. 